\title{
The lean burn direct injection jet ignition gas engine
}

\author{
Alberto A. Boretti*, Harry C. Watson \\ School of Science and Engineering, University of Ballarat, PO Box 663, Ballarat, Victoria 3353, Australia
}

\section{Introduction}

Main chamber (MC) direct injection (DI) of fuel with fast actuating, high flow rate, high pressure injectors capable of injection shaping and multiple events and MC jet ignition (II), with ignition by spark or auto ignition in a small volume pre chamber (PC) providing minimal complication of cylinder head design with PC mixture preparation by PC DI [1,2] has never been considered before for both stationary and trans port applications. In large volume PC ignition systems for large gas engines, the PC fuel is not negligible, the cylinder head design is strongly affected, and PC combustion is important also in itself and not just in initiating MC combus tion, whereas in standard DI injectors, the DI injector is a traditional, low cost, slow actuating, solenoid, low pressure, low flow rate injector and lastly with standard MC spark ignition coupled to DI, combustion is wall initiated with a relatively small energy supply in just one location [3 11]. DI has been shown as the most promising technology to develop gas fueled engines (with hydrogen in the HyICE project [12], compressed natural gas in the NICE project $[13,14]$ or compressed natural gas and hydrogen blends [15,16]). Advanced DI for lean stratified mixtures coupled with bulk high energy JI is the subject explored in this paper.

The new generation, fast actuating, high pressure, and high flow rate DI injector capable of injection shaping and multiple events produces a bulk, lean, jet controlled, stratified mixture. Late DI overcomes the air displacement effects of port fuel injection (PFI) of gaseous fuels. High energy bulk ignition is then achieved by using PC JI. The proposed ignition $\mathrm{PC}$ is very small in size, just a few percent of the combustion chamber volume at top dead centre (TDC) roughly about

\footnotetext{
* Corresponding author. School of Science and Engineering, University of Ballarat, P.O. Box 663, Ballarat, Victoria 3353, Australia. E mail address: a boretti@yahoo.com (A.A. Boretti).
} 
$1 \mathrm{~cm}^{3}$, and designed to be fitted within the traditional spark plug thread $\Phi 14 \mathrm{~mm}$. The ignition device therefore only marginally increases the level of complexity of designing a cylinder head with a standard spark plug. The jets of react ing gases from the ignition PC enhance the rate of combustion of the MC mixture and allow bulk ignition and combustion for reduced heat losses and faster heat release. The coupling of JI and DI technologies allows development of an engine permitting operation with the overall fuel to air equivalence ratios reducing almost to zero, because combustion is always started in the JI PC providing there is a very small amount of fuel, and jets of hot reacting gases from the JI PC may extend combustion to globally very lean MC mixtures providing only a minimum amount of fuel is behind the JI nozzle thus repli cating diesel like light load operation. This new concept recently proposed by the authors [1,2] is described in better detail in Section 2.

\section{The lean burn direct injection jet ignition engine}

The lean burn DI JI [1,2] is an internal combustion engine (ICE) developed to more efficiently and completely burn within the cylinder of a four stroke engine with or without supercharging or turbocharging for non stationary or stationary applications lean mixtures of a variety of fuels, including fuels liquid and vapor under normal conditions. This engine uses a fuel injection and mixture ignition system comprising:

- One MC DI fuel injector per engine cylinder;

- One JI device per engine cylinder, the latter being made of:

- one PC connected to the MC through one or more cali brated orifices;

- one PC DI fuel injector;

- one PC SP (SI version) or one PC GP (auto ignition version).

- All the ancillaries required to supply the fuel at the desired pressures by the DI injectors and operate the DI injectors and the SP or the GP.

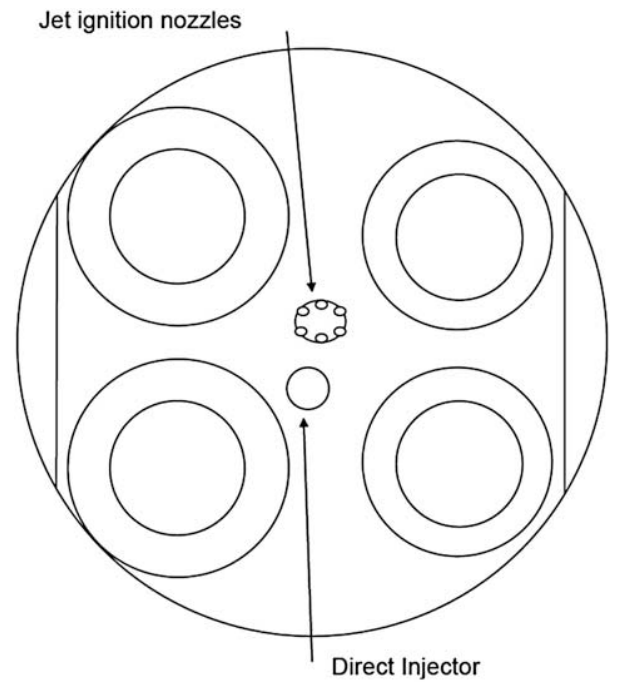

Fig. 1 - Cylinder head layout of the four valve direct injection jet ignition engine.

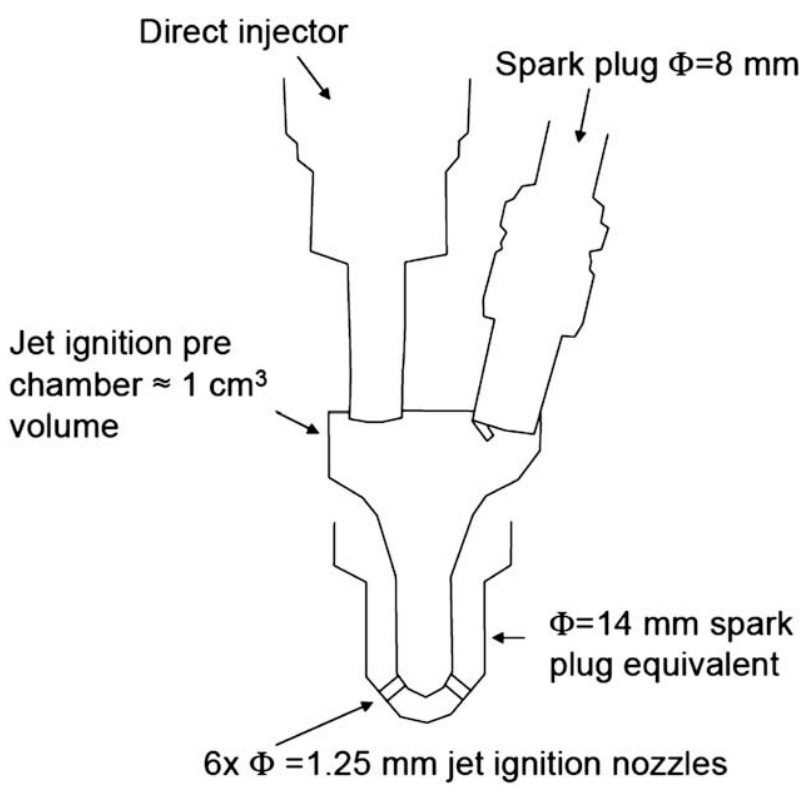

Fig. 2 - Jet ignition assembly for the four valve direct injection jet ignition engine in the version with a spark plug.

The fuel injection and mixture ignition system operation is described as follows:

- One fuel is injected directly within the cylinder by a MC direct injector operating one single or multiple injections to

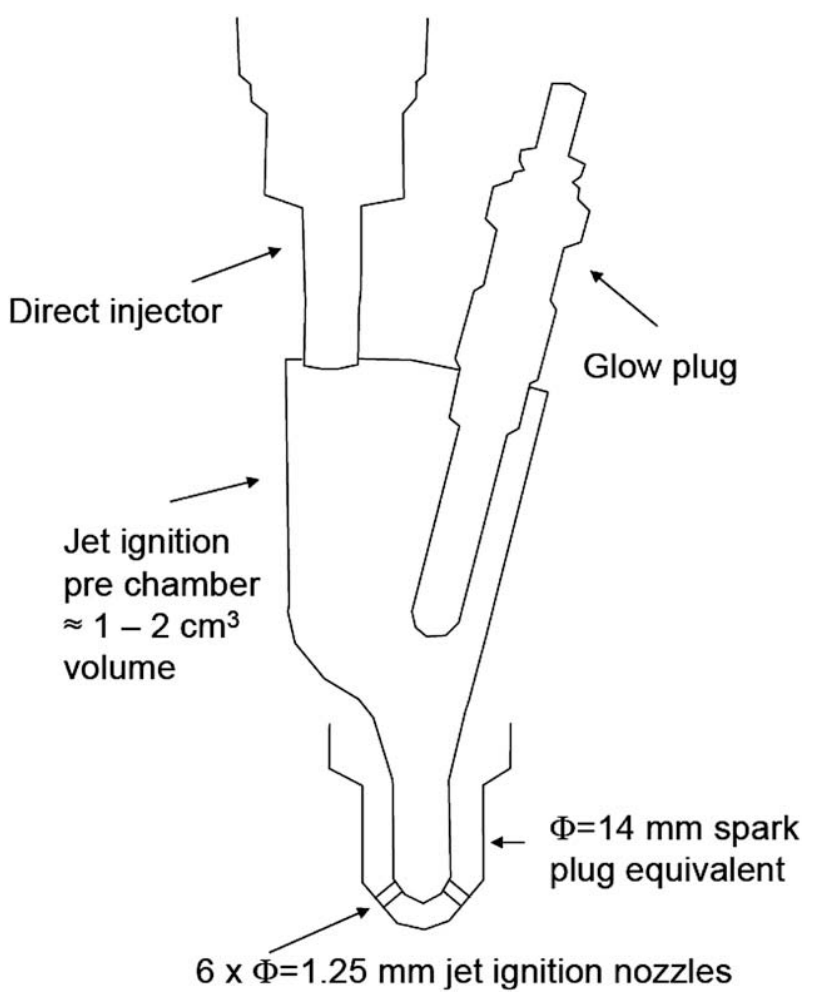

Fig. 3 - Jet ignition assembly for the four valve direct injection jet ignition engine in the version with a glow plug. 


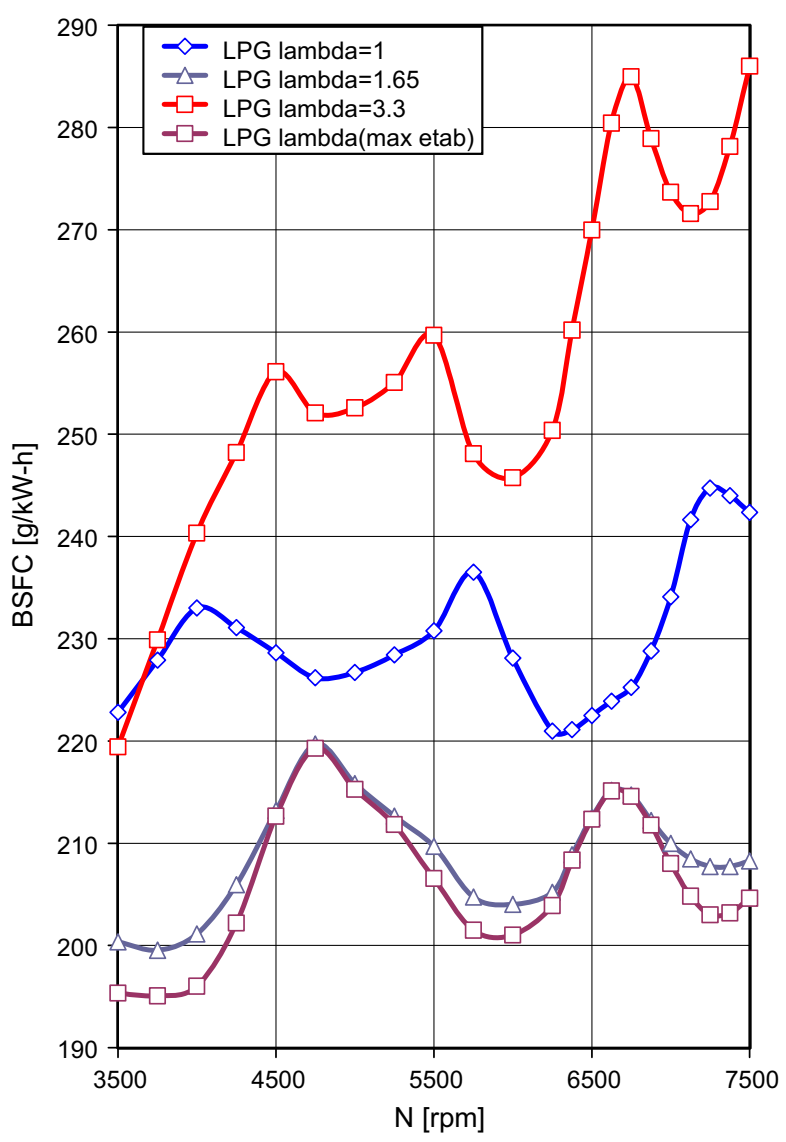

Fig. 4 - BSFC with propane fuel at WOT and MBT or knock limited spark timing - naturally aspirated engine.

produce a lean stratified mixture. This non homogeneous mixture is mildly lean in an inner region surrounded by air and some residuals from the previous cycle. The extension of the inner region may be reduced in size to achieve mean chamber average mixtures ranging from slightly to extremely lean.

- This mixture is then ignited by (one or more, generally more jets) of reacting gases that are issued from a pre chamber connected to the MC via calibrated orifices, sourced from the same or an alternative fuel that was injected into it by a direct injector and then ignited by a spark plug discharge (spark plug version) or auto ignites at a hot glow plug surface (version without spark plug).

- Combustion started slightly fuel rich in the very small volume PC moves to the MC through one or more JI nozzles, with one or more jets of reacting gases bulk igniting the MC mixture. The jets of reacting gases enhance the combustion of lean stratified mixtures within the MC through a combi nation of thermal energy and the presence of active radical species.

With reference to homogeneous DI or PFI and MC spark ignition, non homogeneous DI and JI offer the advantage of:

- much faster, more complete, and much leaner combustion;

- less sensitivity to mixture state and composition;

- reduced heat losses to the MC walls.

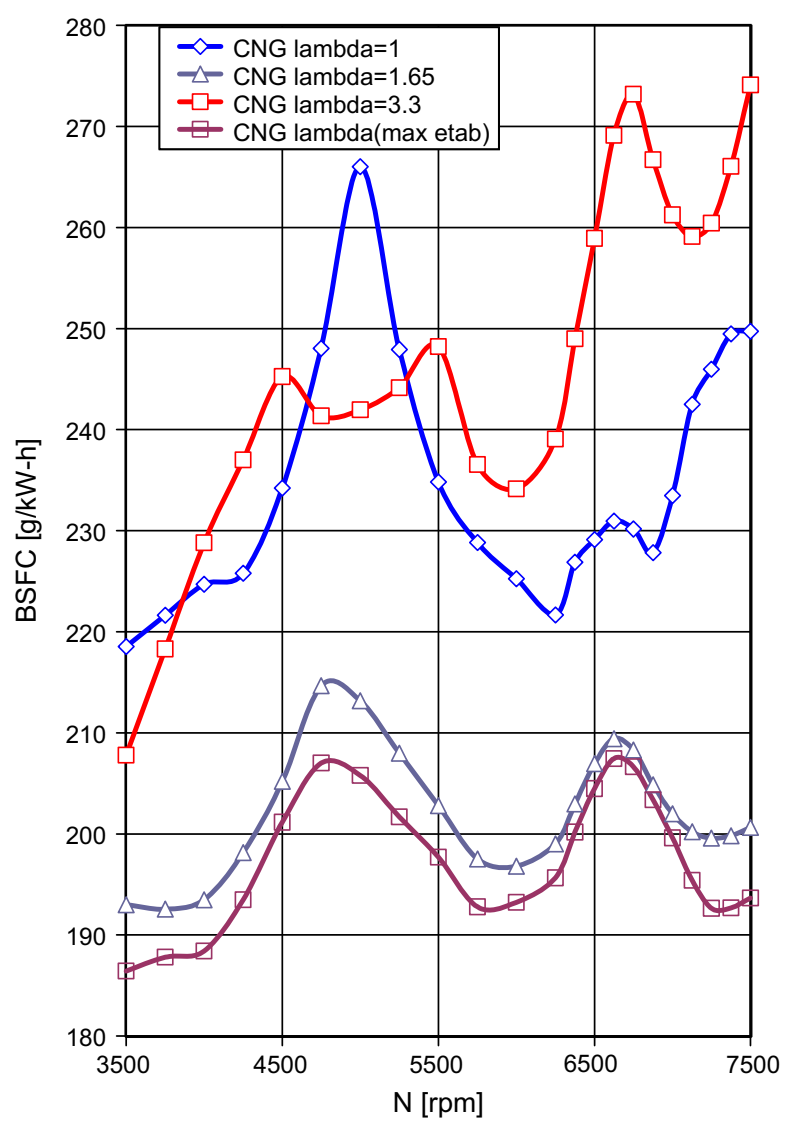

Fig. 5 - BSFC with methane fuel at WOT and MBT or knock limited spark timing - naturally aspirated engine.

This is because of better fuel for the same chamber aver aged lean conditions, combustion in the bulk of the in cylinder gases, heat transfer cushion of air between the hot reacting gases and walls, very high ignition energy at multiple simultaneous ignition sites igniting the bulk of the in cylinder gases, aided by large concentrations of partially oxidized combustion products initiated in the PC that accelerate the oxidation of fresh reactants.

Advantages of the system are as follows:

- Larger brake efficiency (ratio of engine brake power to the total fuel energy) and therefore reduced brake specific fuel consumption (ratio of engine fuel flow rate to brake power) for improved full load operation of stationary and transport engines.

- Efficient combustion of variable quality fuel mixtures from globally near stoichiometry to globally extremely lean en abling load control mostly throttle less by quantity of fuel injected for improved part load operation of non stationary engines.

- Opportunity in the ultra lean mode to produce near zero $\mathrm{NO}_{x}$.

Fig. 1 presents a sketch of the cylinder head layout for a sample four valve pent roof combustion chamber applica tion of the DI JI engine, while Figs. 2 and 3 present a picture of the JI assembly in the versions with or without SP. Lean 


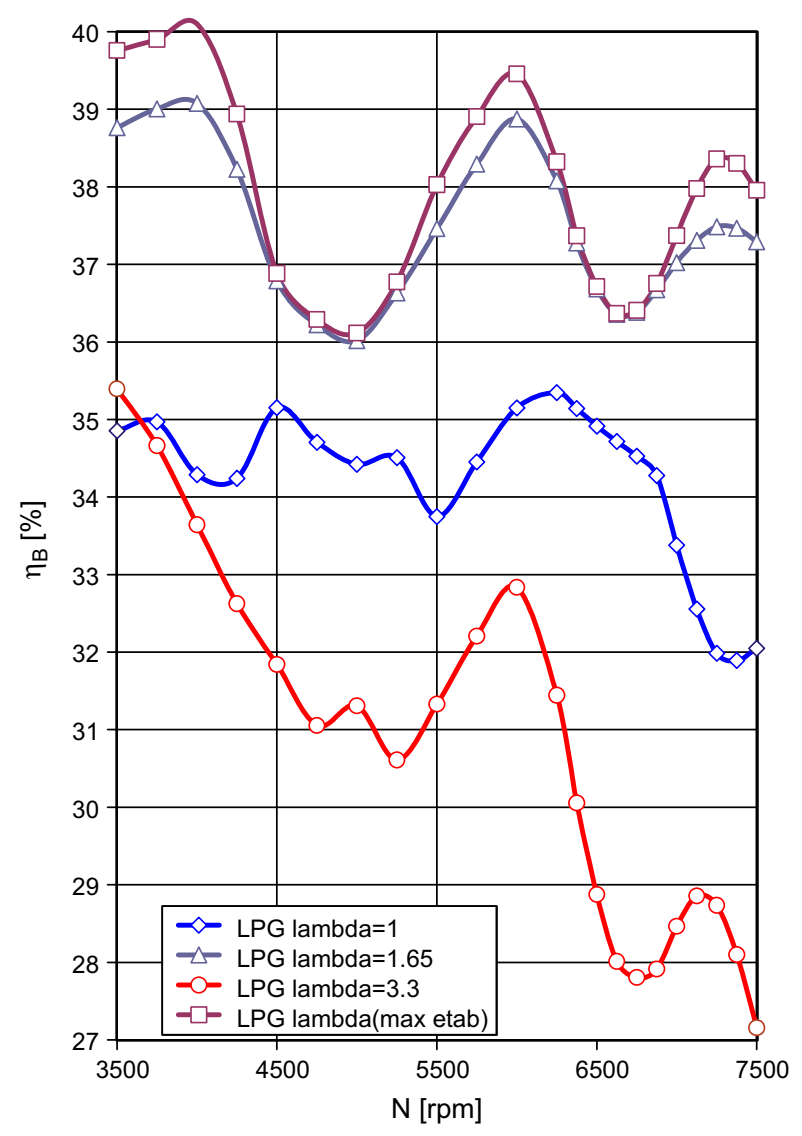

Fig. $6-\eta_{\mathrm{B}}$ with propane fuel at WOT and MBT or knock limited spark timing - naturally aspirated engine.

stratified mixtures are possible adopting charge motion controlled by jet and shaped piston surface/wall or fully jet controlled configurations. The JI pre chamber has 6 nozzles.

Prototype JI devices have been built using low cost gasoline DI injectors providing the requested low flow rates with gaseous fuel and small diameter racing SP placed at the top of a JI PC having a volume of about $1 \mathrm{~cm}^{3}$. The spark ignition (SI) version has the advantage of the reduced size of the PC, better packaging and smoother and reliable operation, while the version without SP has the advantage of avoiding the SP for reduced maintenance costs. Fuel options considered so far include for PC fuel hydrogen, propane vapor or methane and hydrogen, propane vapor, propane liquid, methane or gaso line for MC fuel. Sample applications are presented in Section 3 with propane vapor and liquid and methane.

\section{Computational proofs of concept}

The concept has been applied to a 1.5 liter spark ignition (SI) four cylinder gasoline engine with double over head camshafts and four valves per cylinder. This engine is a V Four 1.5 liters engine, with a bore $78 \mathrm{~mm}$, stroke $78 \mathrm{~mm}$, intake valve seat insert inside diameter $32 \mathrm{~mm}$, exhaust valve seat insert inside diameter $26 \mathrm{~mm}$, connecting rod length $109 \mathrm{~mm}$, and pent roof combustion chamber. The engine has been modeled with GT POWER [17 22]. GT POWER is the

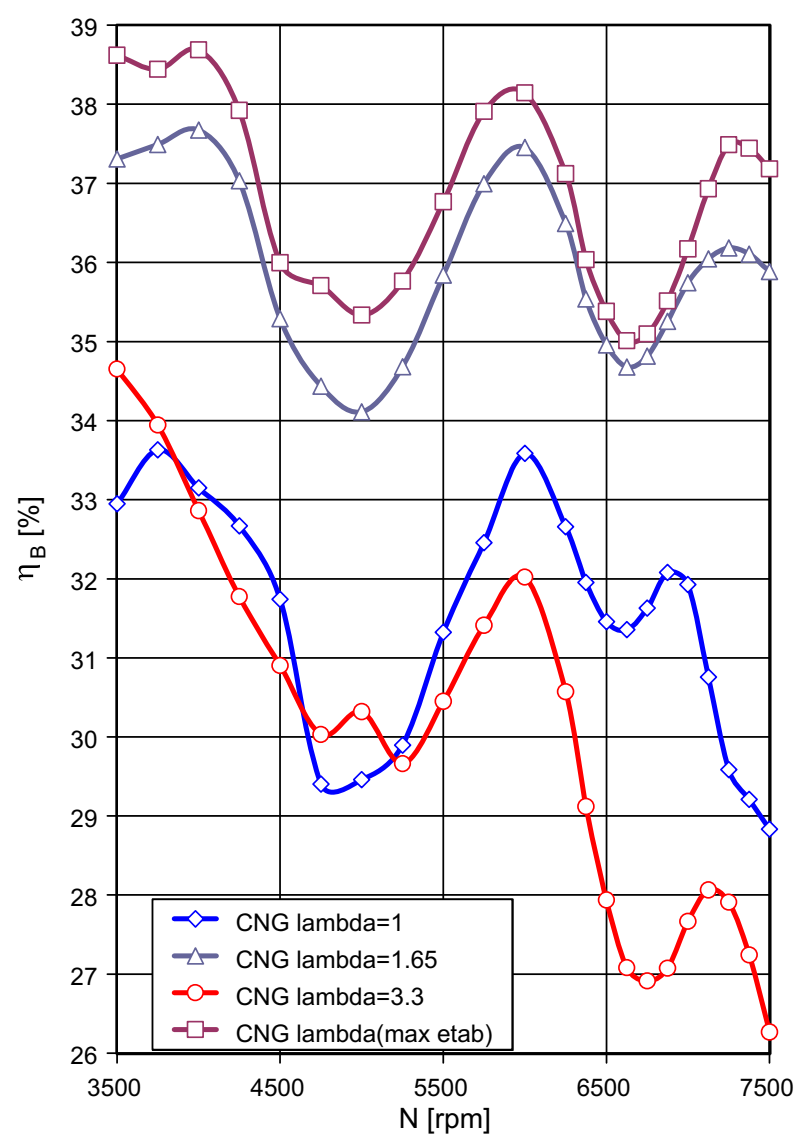

Fig. $7-\eta_{B}$ with methane fuel at WOT and MBT or knock limited spark timing - naturally aspirated engine.

industry standard engine simulation tool, used by most leading engine and vehicle makers and their suppliers. Better details of the model are presented in Refs. [18 21].

The model has been derived from a validated high perfor mance engine model with PFI of gasoline [22]. Main differ ences are stroke and lengths of primary intake and exhaust pipes to accommodate reduced maximum torque and power engine speeds, compression ratios, valve events, the JI replacing the standard spark plug, the DI injector and the fuels. Compression ratios have been selected on the basis of knock index computations. The selected compression ratios produce knock index results close to those obtained for the validated high performance engine model with PFI of gasoline.

The rate of combustion is computed with the predictive combustion model for stoichiometric homogeneous condi tions. The rate of combustion is then imposed in a lean stratified operation by using a Wiebe function with $50 \%$ fuel burned anchored at $7.5^{\circ}$ crank angle after TDC and $1090 \%$ combustion duration given as follows:

$\theta_{10-90}(\lambda \gg 1, s) \quad \frac{\theta_{10-90}(\lambda \quad 1, h)}{\lambda^{\beta}}$

where $\lambda$ is the air to fuel equivalence ratio, $\theta_{10-90}(\lambda \quad 1, h)$ the value computed by the predictive model for stoichiometric $\lambda 1$ homogeneous combustion, $\theta_{10-90}(\lambda>1, s)$ is the value used in the Wiebe function prescription for lean $\lambda>1$ stratified combustion and $\beta$ is a correlation coefficient smaller than 


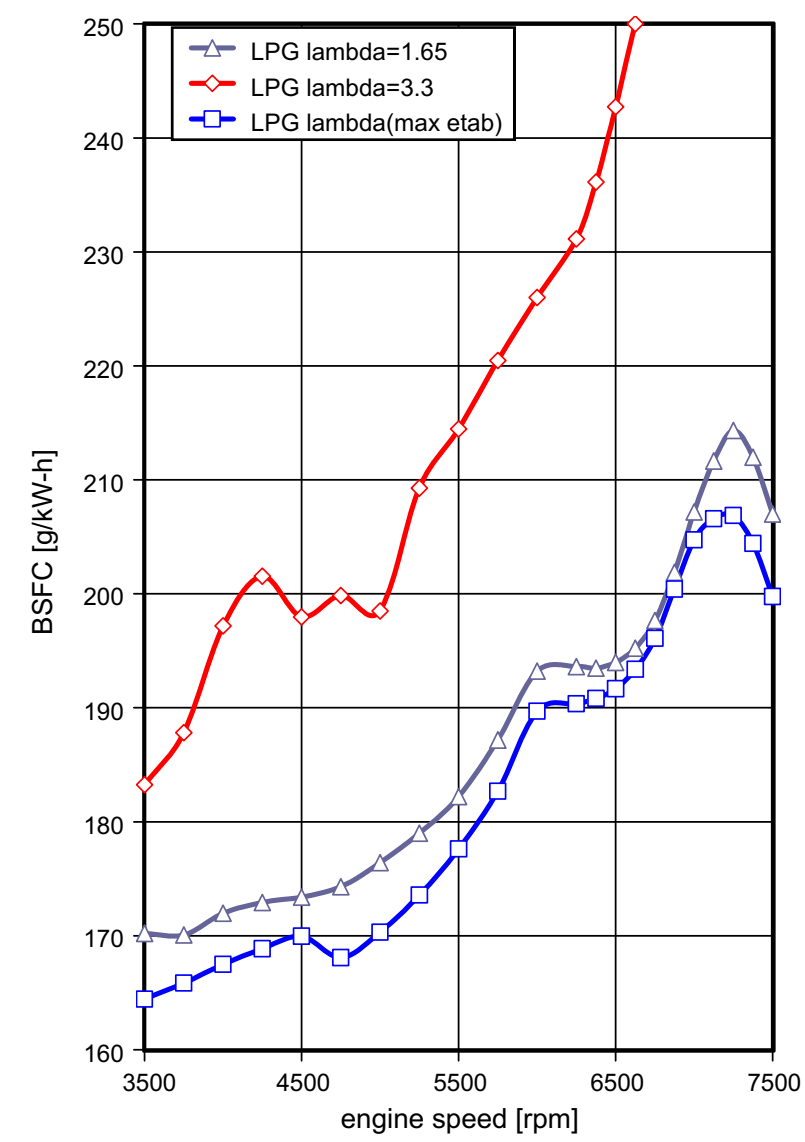

Fig. 8 - BSFC with propane liquid fuel at WOT and MBT or knock limited spark timing - turbocharged engine.

unity. The rate of heat transfer is also decreased introducing a heat transfer multiplier proportional to $\lambda^{\gamma}$ where $\gamma$ is another correlation coefficient smaller than unity. This formulation produces very fast combustion with reduced heat losses that in turn produces very high peak pressures also running very lean, namely 6085 bars in naturally aspirated applications and 90120 bars in turbocharged applications.

ICEs generally have different brake specific fuel consumption (BSFC) values at different speeds and loads [23]. If BMEP, IMEP and FMEP are brake, indicated and friction mean effective pressures, ISFC and FSFC the indicated and friction specific fuel consumption, $N$ is the engine speed and FMR the fuel mass flow rate, then

$\frac{1}{\mathrm{BSFC}} \equiv \frac{\mathrm{BMEP} \cdot \mathrm{N}}{\mathrm{FMR}} \quad \frac{\mathrm{IMEP} \cdot \mathrm{N}}{\mathrm{FMR}} \quad \frac{\mathrm{FMEP} \cdot N}{\mathrm{FMR}} \quad \frac{1}{\mathrm{ISFC}} \quad \frac{1}{\mathrm{FSFC}}$

In a throttle controlled, homogeneous, stoichiometric $\lambda 1$, SI gasoline engine, minimum BSFC is usually found about the peak BMEP operation with the intake not throttled [23]. If $N$ increases, BSFC increases mostly because of the rising FMEP; while if $N$ reduces, BSFC increases mainly because of the increased time for heat transfer to the cylinder walls reducing IMEP, and if the intake is throttled, BSFC increases for the larger pumping losses and therefore the reduced IMEP.

In the DI JI engine, the fast nearly adiabatic lean bulk combustion will deliver lower minimum BSFCs, while the load control by the quantity of fuel injected will keep low the BSFCs

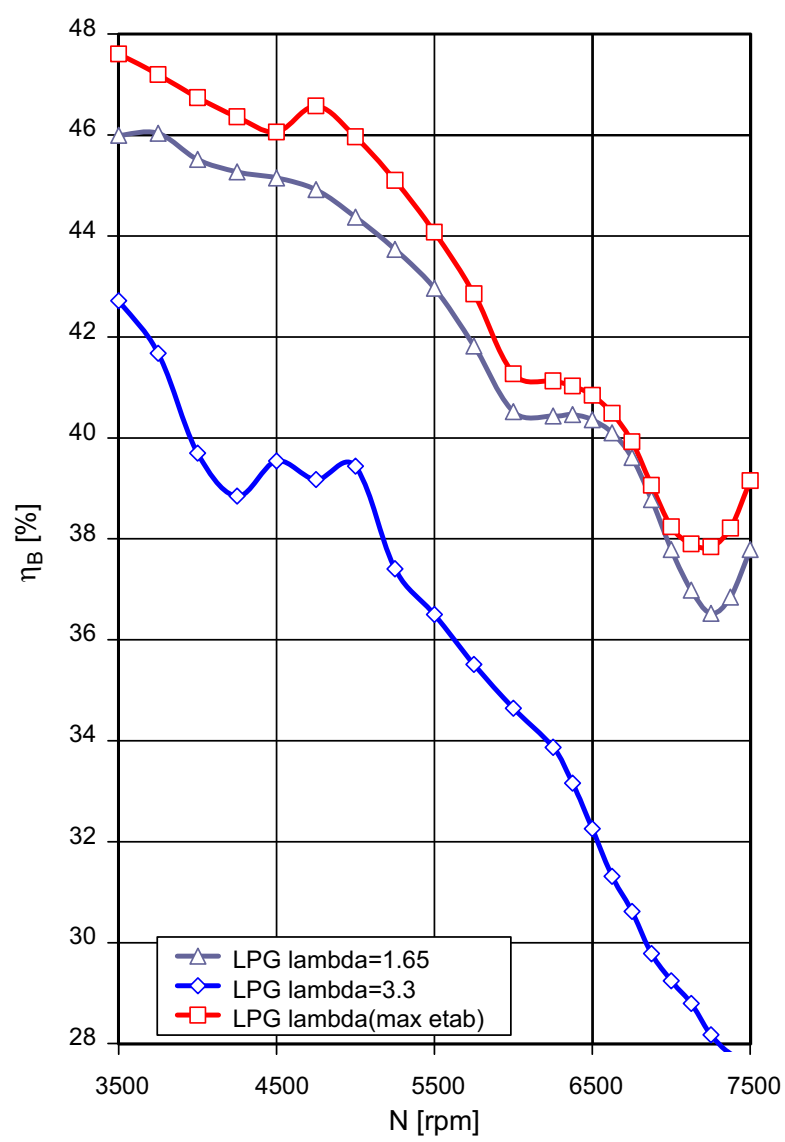

Fig. $9-\eta_{B}$ with propane liquid fuel at WOT and MBT or knock limited spark timing - turbocharged engine.

over most part of the load range, because of the improved ISFC. Increasing $\lambda$ generally reduces ISFC but also increases FSFC, having FMEP only weakly dependent on $\lambda$. Increasing $\lambda$ therefore reduces BSFC only up to a minimum with $\lambda$ slightly larger than $2[20,22]$, then it increases BSFC. Increasing $\lambda$, the BSFC increase running higher engine speeds becomes more relevant as the ratio FMEP/IMEP increases with $\lambda$.

\subsection{Naturally aspirated flexi-fuel propane/methane engine}

The compression ratio CR 13.5 produces knock index results with propane close to those obtained for the validated high performance engine model with PFI of gasoline. The value CR 13.5 is close to the one proposed for the AVL methane DI system in the NICE project $[13,14]$, where CR 14 is used for natural aspiration and CR 13 is used for charged operation.

Results for brake specific fuel consumption BSFC (ratio of engine fuel flow rate to brake power) and brake efficiency $\eta_{B}$ (ratio of engine brake power to the total fuel energy) are pre sented in Figs. 47 for the naturally aspirated version fueled with methane or propane vapor (dual fuel option). The engine produces BSFC values of $200 \mathrm{~g} / \mathrm{kW}$ h with propane and $190 \mathrm{~g} /$ $\mathrm{kW} \mathrm{h}$ with methane operating with $\lambda$ 1.65. Better brake efficiencies $\eta_{B}$ up to $40 \%$ with propane and $39 \%$ with methane are achieved operating slightly leaner with $\lambda$ of about 1.72 .2 


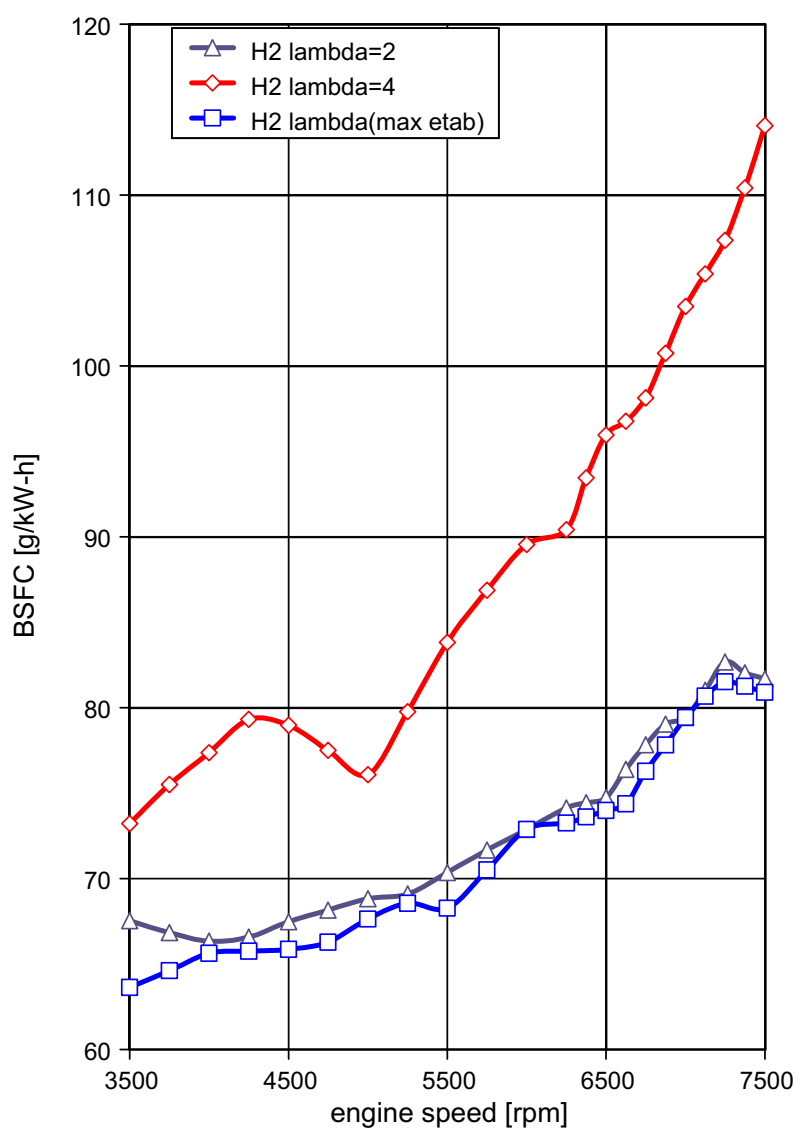

Fig. 10 - BSFC with hydrogen fuel at WOT and MBT or knock limited spark timing - turbocharged engine.

with propane and 1.92.25 with methane over the engine speed range of $35007500 \mathrm{rpm}$.

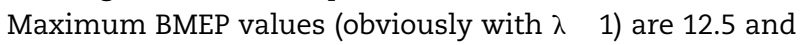
10 bars at $7000 \mathrm{rpm}$ respectively with propane and methane. These high BMEP values provide maximum power densities of $80 \mathrm{hp} /$ liter (60 kW/liter) with methane and almost $90 \mathrm{hp} / \mathrm{liter}$ (67 kW/liter) with propane $[19,21]$.

When load variations are obtained by varying the air to fuel equivalence ratio from stoichiometric $\lambda 1$ up to $\lambda$ 6.6, high efficiencies and low BSFCs are possible from $25 \%$ to $100 \%$ load with both propane and methane. Further improvements of top brake efficiencies $\eta_{B}$ up to 5\% are possible turbocharging the engine.

Considering the traditional throttled port fuel injected homogeneous $\lambda 1$ gasoline engine having a BSFC not less than $220 \mathrm{~g} / \mathrm{kW}$ h in the best full load operating points, corresponding to $700 \mathrm{~g} / \mathrm{kW} \mathrm{h}$ of $\mathrm{CO}_{2}$, the naturally aspirated flexi gas fuel propane/methane engine permits a reduction of $\mathrm{CO}_{2}$ produc tion up to $600 \mathrm{~g} / \mathrm{kW} \mathrm{h}$ with propane and $520 \mathrm{~g} / \mathrm{kW} \mathrm{h}$ with methane over a significantly large portion of the load range for a huge percentage reduction of greenhouse gas emissions.

\subsection{Turbocharged liquid phase propane engine}

The compression ratio CR 14.2 produces knock index results with propane liquid and turbocharging with charge cooling close to those obtained for the validated high performance

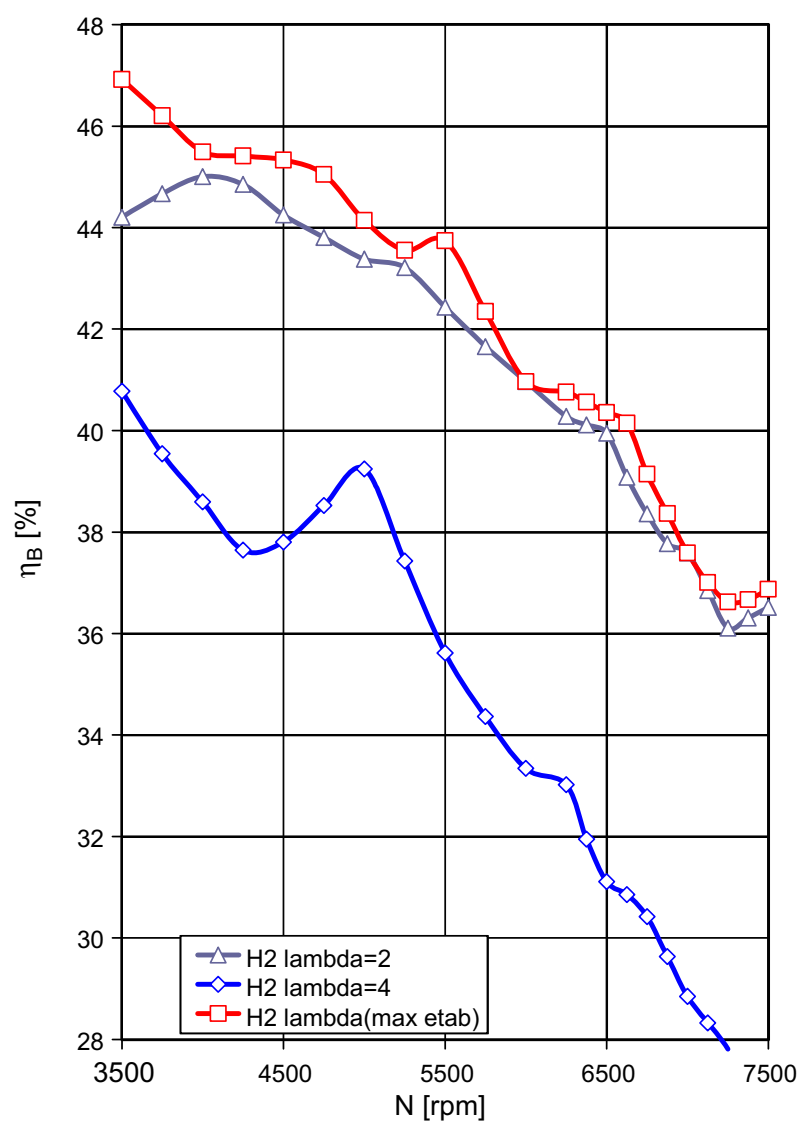

Fig. $11-\eta_{B}$ with hydrogen fuel at WOT and MBT or knock limited spark timing - turbocharged engine.

engine model with PFI of gasoline. This value is close to the one proposed for the AVL methane DI system in the NICE project $[13,14]$, where $C R \quad 14$ is used for natural aspiration and $C R \quad 13$ is used for charged operation.

BSFC and brake efficiency $\eta_{B}$ results are presented in Figs. 8 and 9 for the turbocharged version fueled with propane liquid. The engine with propane liquid injected in the MC has a BSFC as low as $170 \mathrm{~g} / \mathrm{kW}$ h or brake efficiencies $\eta_{\mathrm{B}}$ as high as $46 \%$ while the maximum BMEP is 23 bars at 3500 rpm operating lean with $\lambda$ 1.65. Maximum power densities running $\lambda \quad 1.65$ are more than $140 \mathrm{hp} /$ liter (more than $100 \mathrm{~kW} /$ liter) with propane [20].

Further improvements of brake efficiencies $\eta_{B}$ of about 1 $2 \%$ are possible operating leaner than $\lambda$ of about 1.72 .2 over the speed range of $35007500 \mathrm{rpm}$. When load variations are obtained by varying the air to fuel equivalence ratio from $\lambda 1.65$ up to $\lambda$ 6.6, high efficiencies and low BSFCs are possible from $25 \%$ to $100 \%$ load.

With reference to the traditional throttled port fuel injected homogeneous $\lambda 1$ gasoline engine, the turbocharged liquid phase propane engine permits a reduction of $\mathrm{CO}_{2}$ production up to $510 \mathrm{~g} / \mathrm{kW}$ h over a significantly large portion of the load range for a huge percentage reduction of greenhouse gas emissions.

\subsection{Turbocharged hydrogen engine}

The compression ratio adopted here is CR 14.5. The selected compression ratio produces knock index results close to those 
obtained for the validated high performance engine model with PFI of gasoline.

BSFC and brake efficiency $\eta_{B}$ results are presented in Figs. 10 and 11 for the turbocharged version fueled with hydrogen.

With $\lambda=2$, the engine has a BMEP approaching 24 bars at $3500 \mathrm{rpm}$, while the BSFC is as low as $65 \mathrm{~g} / \mathrm{kW}$-h, or brake efficiencies $\eta_{B}$ are as high as $46 \%$, approaching $3500 \mathrm{rpm}$. Further improvements of brake efficiencies $\eta_{B}$ of about $1-2 \%$ are possible operating slightly leaner than $\lambda=2$ especially in the low range of engine speed.

When load variations are obtained by varying the air to fuel equivalence ratio from $\lambda=2$ up to $\lambda=4$, high efficiencies and low BSFCs are possible from about $25 \%$ load.

\section{Conclusions}

Coupling of jet ignition (II) and direct injection (DI) allows the development of an engine permitting operation, with the overall fuel to air equivalence ratios reducing almost to zero from nearly stoichiometric for diesel-like throttle-less control of load.

Combustion always starts in the JI pre-chamber (PC) providing a very small amount of fuel is injected there to produce an ignitable mixture. The jets of hot reacting gases from the PC then extend combustion to a main chamber (MC) mixture that may be globally very lean having only a minimum amount of fuel available behind the JI nozzle thus replicating the diesel-like light load operation.

The system delivers larger brake efficiency (ratio of engine brake power to the total fuel energy) and therefore reduced brake specific fuel consumption (ratio of engine fuel flow rate to brake power) for improved full load operation of stationary and transport engines.

The system also offers the advantage of having efficient combustion of variable quality fuel mixtures from globally near stoichiometry to globally extremely lean enabling load control mostly throttle-less by quantity of fuel injected for improved part load operation of non stationary engines.

The proposed technology significantly reduces fuel consumption and greenhouse gas emissions with reference to traditional throttled port fuel injected (PFI) homogeneous $\lambda=1$ gasoline engines at full load and much more at part load.

\section{R E F E R E N C E S}

[1] Boretti A, Watson HC. Lean burn direct injection jet ignition internal combustion engine. IP Australia provisional patent application SPEP-11865853(2009901639), April 17, 2009.

[2] Boretti A, Watson HC. Lean burn direct injection jet ignition internal combustion engine without spark plug. IP Australia provisional patent application SPEP-11928154(2009901961), May 5, 2009.

[3] Cathcart G, Caley D. Development of a natural gas spark ignited direct injection combustion system. Paper presented to the NGV2006 conference, Cairo, Egypt, November 2006, $<$ www.orbeng.com.au/orbital/tp/pdf/2006_ngv.pdf > (retrieved April 20, 2009).

[4] Hochstadt H. Compressed natural gas direct injection (methane-DI): a growth opportunity. <www.dpi.wa.gov.au/ mediaFiles/alt_confharoldhochstadt.pdf $>$ (retrieved April 20, 2009).
[5] Podnar DJ, Kubesh JT. Development of the next generation medium-duty natural gas engine. Southwest research institute report NREL/SR-540-27503, February 2000, <www. nrel.gov/docs/fy00osti/27503.pdf> (retrieved April 20, 2009).

[6] John Kubesh T. Development of a throttle-less natural gas engine. Southwest research institute report NREL/SR-54031141, February 2002, <www.nrel.gov/docs/fy02osti/31141. pdf $>$ (retrieved April 20, 2009).

[7] Olsen Daniel B, Kirkpatrick Allan T. Experimental examination of prechamber heat release in a large bore natural gas engine. Journal of Engineering for Gas Turbines and Power September 2008;130.

[8] Corey Honl. Ignition improvements to support highefficiency and turbulent natural gas combustion. Paper presented to the 2005 UW ERC symposium on low-emissions combustion technologies for internal combustion engines, madison, WI, USA, June 8-9, 2005.

[9] Alan C. Anderson. The SIP combustion system for NOx reductions on existing Dresser-Rand gas engines. Collection of Dresser-Rand technical papers, <www.dresser-rand.com/ e-tech/PDF\%20Files/tp014.pdf> (retrieved April 20, 2009).

[10] <www.wartsila.com/Wartsila/global/docs/en/power/media publications/brochures/engines/wartsila_34SG_engine_ technology.pdf $>$ (retrieved April 20, 2009).

[11] <www.manbw.com/files/news/filesof9805/4520-000302web_stationary.pdf $>$ (retrieved April 20, 2009).

[12] <http://ec.europa.eu/research/transport/projects/article_ 5027_en.html $>$.

[13] <http://ec.europa.eu/research/transport/projects/article_ 5054_en.html $>$.

[14] <www.avl.com> (retrieved April 20, 2009).

[15] Wang Jinhua, Huang Zuohua, Fang Yu, Liu Bing, Zeng Ke, Miao Haiyan, et al. Combustion behaviours of a directinjection engine operating on various fractions of natural gas-hydrogen blends. International Journal of Hydrogen Energy 2007;32(15):3555-64.

[16] Huang Zuohua, Wang Jinhua, Liu Bing, Zeng Ke, Yu Jinrong, Jiang Deming. Combustion characteristics of a directinjection engine fuelled with natural gas-hydrogen blends under different ignition timings. Fuel 2007;86(3):381-7.

[17] <www.gtisoft.com/broch_gtpower.html> (retrieved April 20, 2009).

[18] Boretti AA, Watson HC. Development of a direct injection high efficiency liquid phase LPG spark ignition engine. Paper published in the SAE 2009 international powertrains, fuels and lubricants meeting, Florence, Italy, June 15-17, 2009, SAE P. 2009-01-1881.

[19] Boretti AA, Watson HC. Development of a direct injection high flexibility CNG/LPG spark ignition engine. Paper published in the SAE 2009 international powertrains, fuels and lubricants meeting, Florence, Italy, June 15-17, 2009, SAE P. 2009-01-1969.

[20] Boretti AA, Watson HC. The lean burn direct-injection jetignition turbocharged liquid phase LPG engine. Paper submitted for presentation to the 15th Asia Pacific automotive engineering conference (APAC-15), Hanoi, Vietnam, October 2009.

[21] Boretti AA, Watson HC. The lean burn direct-injection jetignition flexi gas fuel LPG/CNG engine. Paper submitted for presentation to the 2009 SAE powertrains, fuels and lubricants meeting, San Antonio, Texas, USA, November 2009, SAE P. 09FFL-0037.

[22] Boretti AA, Watson HC. Comparison of PFI and DI super bike engines. Paper published in the 2008 SAE motor sports engineering conference, Concord, North Carolina, USA, December 2008, SAE P. 2008-01-2943.

[23] <http://en.wikipedia.org/wiki/Brake_specific_fuel_ consumption $>$. 